hypothesized that the HLA-linked defect involves a structural gene for this protein. Their test of that hypothesis was facilitated by the knowledge that different forms of the disease are associated with characteristic HLA-B;DR antigens, and that 21-hydroxylase deficiency is in linkage disequilibrium with complement allotypes. For instance, all patients with the haplotype $H L A-(A 3) ; B w 47 ; D R 7$ are deficient in both the complement protein $\mathrm{C} 4$ and 21-hydroxylase. This led White et al. to the additional hypothesis that the genes for $\mathrm{C} 4$ and 21-hydroxylase are closely linked and that patients with the Bw47 haplotype may have a large genetic deletion or rearrangement affecting both these genes.

This hypothesis was tested by the use of a cDNA clone coding for bovine $\mathrm{P}-450_{\mathrm{C} 21}$ (ref. 5) to analyse the organization of the $\mathrm{P}-450_{\mathrm{C} 21}$ gene in human DNA. Normal individuals are found to have two $\mathrm{P}-450_{\mathrm{C} 21}$ genes. In the only patient homozygous for both 21-hydroxylase deficiency and HLABw47 antigen, one of the $\mathrm{P}-450_{\mathrm{C} 21}$ genes is deleted. Of patients homozygous for the deficiency but heterozygous for $B w 47$, one carries a homozygous deletion of a $\mathrm{P}-450_{\mathrm{C} 21}$ gene whereas the others all have heterozygous deletions. The deletions segregate with the $B w 47$ haplotype over three generations. Thus the $H L A-B w 47$ associated 21-hydroxylase deficiency is due to a deletion of a $\mathrm{P}-450_{\mathrm{C} 21}$ gene. However, in the majority of cases where the disease is associated with other HLA-B antigens, the defect is presumably due to much smaller mutations, the nature of which remains to be established.

The elucidation of the molecular genetic basis of congenital adrenal hyperplasia will enable prenatal diagnosis at a much earlier stage than is possible with current methods. This is particularly significant because, in principle, it should be possible to alleviate the condition, at least in female foetuses, by treatment of the mother with dexamethasone.

The prediction of White et al. that C4 and $\mathrm{P}-450_{\mathrm{C} 21}$ genes are closely linked is borne out by Carroll et al. ${ }^{3}$, beginning with the demonstration that a segment of human DNA containing the C4 gene hybridizes to a 2.4 kilobase messenger RNA from tissue. Two copies of the gene corresponding to this $\mathrm{mRNA}$ are found to lie 1.5 kilobases downstream of the genes for the complement proteins $\mathrm{C} 4 \mathrm{~A}$ and $\mathrm{C} 4 \mathrm{~B}$ (see figure). The expression of the gene in the adrenal gland, the size of its mRNA and a partial sequence analysis indicate that it encodes a human $\mathbf{P}_{-450_{\mathrm{C} 21}}$. (Using a similar approach, White et al. ${ }^{6}$ have demonstrated there are two $\mathrm{P}-450_{\mathrm{C} 21}$ genes located immediately downstream of the $C 4$ gene and the related $s l p$ gene of the mouse, suggesting that a P-450 ${ }_{\mathrm{C} 21}$ gene became linked to the major histocompatibility complex, and was duplicated along with an adjacent $C 4$ gene, sometime before the divergence of mammals).

In contrast to the genes coding for two

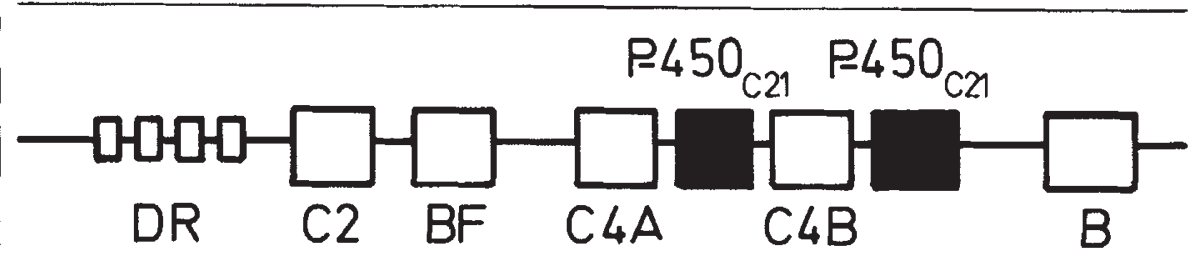

Schematic map (not to scale) of the $H L A$-region of human chromosome 6 containing the pair of $\mathrm{P}-450_{\mathrm{C} 21}$ genes. $\mathrm{C} 2, \mathrm{C} 4 \mathrm{~A}, \mathrm{C} 4 \mathrm{~B}$ and $\mathrm{BF}$ (factor $\mathrm{B}$ ) genes encode complement components; DR genes encode Class II HLA antigens and B gene encodes a Class I HLA antigen.

other complement proteins, $\mathrm{C} 2$ and factor B, which lie one kilobase apart, 30 kilobases upstream from the $C 4 A$ genes (see figure) and which probably arose by duplication of a common ancestral gene, $\mathrm{P}-450_{\mathrm{C} 21}$ and $\mathrm{C} 4$ are not similar in sequence. The significance of their close association is not clear and there is no obvious explanation for the presence in the major histocompatibility complex of genes coding for a steroidogenic enzyme.

The function of the second $\mathrm{P}-450_{\mathrm{C} 21}$ gene is as yet unknown and it would be of interest to establish whether the two $\mathrm{P}-450_{\mathrm{C} 21}$ genes are highly conserved. It will also be interesting to discover the mechanism responsible for regulating the differential expression of the $C 4$ and $\mathrm{P}-450_{\mathrm{C} 21}$ genes in liver and adrenals.

The 21-hydroxylase involved in congenital adrenal hyperplasia is a member of a 'superfamily' of proteins termed cytochromes P-450. Some members of this family, such as $\mathrm{P}-450_{\mathrm{C} 21}$ itself, are involved in the metabolism of endogenous compounds, whereas others play a central role in the metabolism of foreign hydrophobic compounds, including drugs and carcinogens. Three cytochromes P-450 involved in the metabolism of foreign compounds have been mapped to chromosomes 7 and 9 in mouse $\mathrm{e}^{7,8}$ and genes coding for a drug-inducible cytochrome P-450 (ref. 9) have recently been mapped to chromosome 19 in man (E.A.S., I.R.P., M. Davis and S. Povey, unpublished observations). Just as a defect in a $\mathrm{P}-450_{\mathrm{C} 21}$ gene has now been shown to be the cause of congenital adrenal hyperplasia, it is hoped that the availability of cloned DNAs coding for human cytochromes P-450 involved in the metabolism of drugs or chemical carcinogens will lead to a determination of the molecular-genetic basis of inherited variations in the ability of individuals to metabolize these substances.

1. Kuhnle, U. et al. J. clin. endocrinot. Metab. 52, 534 (1981). 2. White, P.G., New, M.I. \& Dupont, B. Proc. natn. Acad. Sct. U.S.A. 81, 7505 (1984).

3. Carroll, M.G., Campbell, R.D. \& Porter, R.R. Proc. natn. Acad. Sci. U.S.A. 82, 521 (1985)

4. Kominami, S., Ochi, H., Kobayashi, Y \& Takemori, S. J. biol. Chem. 255, 3386 (1980).

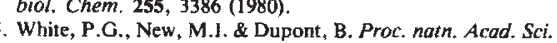
U.S.A. 81, 1986 (1984).

6. White, P.G. et al. Nature 312, 465 (1984).

7. Simmons, D.L. \& Kasper, C.B. J. biol. Chem. 258, 9585 (1983).

8. Tukey, R.H., Lalley, P.A. \& Nebert, D.W. Proc. natn. Acad. Sci. U.S.A. 81, 3163 (1984)

9. Phillips, 1.R., Shephard, E.A., Ashworth, A.\& Rabin, B.R Proc. natn. Acad. Sci. U.S.A. 82, 983 (1985).

Ian R. Phillips is at the School of Pharmacy, University of London, 29-39 Brunswick Square, London WCIN IAX, UK; Elizabeth $A$. Shephard is in the Department of Biochemistry, University College London, Gower Street, London WCIE 6BT, UK.

\title{
100 Years Ago A New American Clock
}

THE accompanying figure from $L a$ Nature illustrates a new American clock of ingenious construction. It is distinguished from all other clocks by the singular and original form of its pendulum, based on the principal of torsion. A train of wheels gives rotation to a vertical axis, which is seen over the case, the rate of motion of which is to be regulated. This vertical axis supports a sort of bracket, $P$, to the extremity of which is attached a small bead or ball, B, by means of a thread a few centimetres long. The axis, by the action of the main spring, will turn with a rapid movement, drawing the ball $\mathrm{B}$ along with it. To regulate this movement, it is sought to interpose in its path suitable obstacles; this is the object of the horizontal wire terminating in the hooks $\mathrm{T}$, and of the vertical pillars fixed on the case. The bracket $P$ draws the thread in its movement and makes it strike against the arm $\mathrm{T}$; it

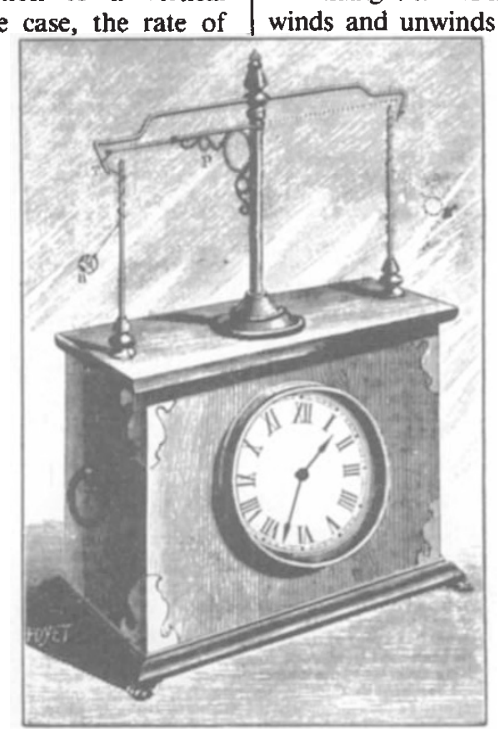

is thus arrested, and by virtue of its acquired speed, the ball B winds the thread around the pillar on the left; then follows an unwinding of the thread and a rewinding in an inverse direction, which enablesthe thread to pass the point $T$. But in unwinding it strikes a second time against the pillar, anew, and only succeeds in passing this double obstacle after four successive windings, twice in one direction, and twice in the opposite direction around the same pillar. The thread thus set at liberty permits the bracket to turn $180^{\circ}$ around the vertical axis. After this rotation it encounters two analogous objects placed on the right of the clock, and is delayed a certain time before passing these objects and returning to the pillar on the right. The clock is thus regulated, if not with all the precision of a chronometer, with an approximation said to be sufficient for ordinary use. From Nature 31 439, 12 March, 1885. 